\title{
A Phenomenological Study of th Passers and Non- Passers in the Licensure Examination for Teachers
}

\author{
Binayao, Bernadette S., PhD \\ Bukidnon State University \\ Malaybalay City, Bukidnon, Philippines
}

\begin{abstract}
The delivery of quality education is gauge with the performance of the graduates in the licensure examination. In the field of education, the Licensure Examination for Teachers (LET) is a tool which assesses the preparedness of teacher education graduate to practice the profession. This study explored the lived experiences of the passers and non-passers in the Licensure Examination for Teachers (LET) of the Bukidnon State University education graduates from the main campus, external centers, and the Certificate of Teaching who took the professional education units during the years 2016-2018. The experiences of the LET-takers with the internal stakeholders and external stakeholders were disclosed. The qualitative phenomenological descriptive method of Creswell (2013) was used in this study. Interviews and focus group discussion were conducted to gather the data and analyzed using Colaizzi (1978) as cited by Morrow and King (2015). The total participants of the study were the 36 LET-takers comprised the 18 passers and 18 nonpassers with two (2) sampled participants from each group. There were six (6) emergent themes transpired from the experiences of the passers and non-passers in LET with the internal stakeholders and the external stakeholders. These were engaging to self-directed undertakings; demonstrating teaching credibility; institutional commitment for quality education; imparting kin-based social support; exhibiting capability and quality; and extending non-kin based social support. An intervention plan to address the areas of concern of the non-passers was designed.
\end{abstract}

Keywords:- Phenomenology, Licensure Examination for Teachers (LET), Passers, Non-Passers.

\section{INTRODUCTION}

Licensure examination is an essential requirement to practice one's profession. It is a primary standard to become a recognized professional in her/his field of expertise. The Licensure Examination for Teachers (LET) is required for every graduate of a teacher education course to practice the teaching profession. More importantly, passing the LET indicates a competitive edge over those who are non-LET passers. Determinant to teachers' competence and safe job performance is the LET performance. The teachers are regarded job-ready after passing the LET, as it confirms effectiveness and efficiency on the competencies of pedagogical content knowledge and skills that a teacher must possess.

\author{
Dales, Zita I., PhD \\ Bukidnon State University \\ Malaybalay City, Bukidnon, Philippines
}

The Accrediting Agency of Chartered Colleges and Universities in the Philippines (AACCUP) has considered the LET as one of the factors that influence the quality of teachers and teaching in the country. The performance in LET has been also identified as one of the output indicators in the Normative Financing Scheme in determining the financial allocations given to State Universities and Colleges (DBM-CHED, 2004). The LET performance is also a significant criterion in the awarding of the Center of Development (COD) and Center of Excellence (COE) by the Commission on Higher Education (CHED) to Higher Education Institutions (HEIs) curricular programs. This is the reason the HEIs are compelled and reinforced to strive and demonstrate excellence in the licensure examination. In response to the reports about the deteriorating quality of teacher education graduates, as reflected in PRC-LET results, the Commission on Higher Education (CHED) has issued the "Revised Policies and Standards for Undergraduate Teacher Education Curriculum" (Memorandum Order No. 30, Series of 2004).

Statistics retrieved from PRC (2019) showed that the LET performance of the education graduates of Bukidnon State University (BukSU) for the last three years was below the national passing percentage. The highest national passing rate for $\mathrm{BEE}$ was $30.18 \%$, which was last September 2016, while the BSE was $48.03 \%$ for the September 2018 result. Further, the LET performance of the BEE and BSE first-time takers averaged to $51 \%$ and $49.50 \%$ in March 2018 and in September 2018, respectively. It showed that $50 \%$ of the first-time LET takers passed while the other $50 \%$ were unsuccessful.

It is alarming in the case of the repeaters that $84 \%$ of BEE and $83 \%$ of BSE LET examinees pulled down the national passing percentage of the university. Fortunately, one of the first-time takers top the examination in the September 2018 national result, which gives the university the honor and the integrity to produce quality graduates. The university did not stop trying its best to deliver quality education; in fact, it yields topnotchers from the previous years 2004, 2010, 2017, 2018, and 2019.

It is noteworthy that the LET-takers had different experiences as recipients of the college's initiatives and intervention programs to prepare them for the exam. Moreover, they may have experienced other factors that were contributory to their passing or failing the exam. Such factors could be in the cognitive, psycho-emotional, social, and physical preparations. Hence, this study explores the experiences of the passers and non-passers in LET. 


\section{$>$ Framework of the Study}

This study was anchored on the Structural-Functional Theory of Durkheim (1898) as cited by Sever (2012). He sees society as a structure with interrelated parts designed to meet the biological and social needs of the individuals and work together to promote solidarity and stability. Education, as one of the social structures, gives shape to lives and has social functions. It teaches every individual how to get along with others and prepare them for societal roles. The teacher education graduates as individuals in the society were molded and prepared by BukSU to face the challenges of LET and become a productive citizen of society as a future educator. The students, teachers, and the school as part of the society were described below by Sever (2012) based on Durkheim's theoretical perspective.

The students are blank sheets, tabula rasa who are ready to be filled with common social goods by the agents or the teachers of society. These students referred to the LET-takers, both the passers and non-passers. From the time they enrolled at BukSU, they were equipped with the necessary competencies and skills for LET and ready to become a worthy educator in the community where they belong.

The teachers are agents of legitimate knowledge transmission. They are moral models and moral beings teaching societal goods. The teachers of BukSU play a significant role in the academic success of students. Furthermore, the school is a significant agency of socialization, the only institutional place that teaches skills and roles. It is a venue that paves the way to equal opportunity that facilitates the promotion of students' standing in the social hierarchy. The BukSU administration, as the functional structure of the institution, provides students with the necessary skills and knowledge they need to function on the broader society.

The Republic Act (RA) 7836 known as the Philippine Teachers Professionalization Act of 1994 supported this study. The Professional Regulation Commission (PRC) strengthened the supervision and regulation of the teaching profession. The PRC then prescribed the Licensure Examination for Teachers (LET). Additionally, Article IV, Section 27 of the same Act stipulates the teachers' appointment to a teaching position in the government is to obtain a valid certificate of registration and a valid professional license from the Commission.

The performance of the graduates in LET entails the collaborative efforts of both the internal and the external stakeholders. These internal stakeholders include the LETtakers, administration, and the faculty. In contrast, the external stakeholders were the family, resource persons and other people who may be indirectly connected to the LETtaker. These people have a wide-range role in the preparation of the students for LET, then to the performance of the graduates in the exam.
This study also anchored on several theories and concept. One of which is the Self-Efficacy Theory of Bandura (1994), which originated from the Social Cognitive Theory of Learning. The theory emphasized that with selfefficacy, an individual accomplishes something and can be useful in completing a given task or activity related to competency. The positive attitude towards studies is essential and inherent to most of the graduates of Bukidnon State University (BukSU). They are capable of reaching their goal, which is to become a licensed professional teacher. However, they need to be competent with the content knowledge and skills required for LET in order to produce positive outcomes.

Moreover, the Self-directed Learning Theory (SDL) of Knowles (1975) as cited by Cottrell (2017) is a process in which individuals take the initiative to determine their learning needs, set learning goals, identify human and material resources for learning, choose and implement appropriate learning strategies, and evaluate learning outcomes. They take responsibility for, and control of, their learning. Taking the licensure examination is a tedious and challenging task. The BukSU graduates learned to set challenging goals and maintain a strong commitment to achieving them. Passing the LET is an achievement; failing is a challenge to increase and sustain their efforts to be successful. They approach difficult or threatening situations with confidence that have control over them.

The study was also backed up by the concept of McCroskey et al. (2004) on the aspect of teachers' credibility, which is one of the most essential elements of teacher effectiveness. Myers and Bryant (2004) identified three dimensions of credibility; these were competence, character, and caring or goodwill. The instructor's competence is conveyed through content expertise, which affects the students, while the instructors' credibility influences student learning, behavior, and outcomes. Instructors are credible when there is an increase in motivation, affective learning, and cognitive learning among students. The LET-takers observed different levels of credibility with their instructors that contribute to their LET performance.

Further, Gottlieb (2007) strengthened the support theory, which referred to the social resources provided to any person in the context of formal support groups and informal helping relationships. These social supports have four dimensions, namely: emotional, esteem, informational, and instrumental.

The emotional support displays the expression of love, and empathy in the form of listening, talking things through, and the provision of moral support. Giving words of encouragement and reassurance to boost confidence, to motivate, and to help deal with the pressure are examples of esteem support. Whereas, the informational support includes the provision of advice, feedback, constructive criticism, and help with decision-making, while instrumental are the tangible goods or services. The LET-takers were directly and indirectly provided with these supports by the family, 
administration, and other stakeholders in varied forms. The kind of support received by each LET-taker depends on the degree of proximity in the social network.

\section{Objectives of the Study}

This study explored the lived experiences of the passers and non-passers in the Licensure Examination for Teachers (LET) of the education graduates of Bukidnon State University during the examination schedules in March and September of 2016-2018.

Specifically, it aimed to (1) uncover the experiences of the passers and non-passers in Licensure Examination for Teachers (LET) with the Internal Stakeholders (i.e. LETtakers, instructors, and administration) and External Stakeholders (i.e. family, resource persons, and other stakeholders (2) design an intervention plan to improve the performance of the graduates in the Licensure Examination for Teachers (LET).

\section{- Legal Bases of the Licensure Examination for Teachers (LET)}

The Licensure Examination for Teachers (LET) is a mandatory appraisal of professional teachers. It is mandated by RA 7836 to fortify the directive and supervision of the Practice of Teaching in the Philippines. It is also prescribing a Licensure Examination for Teachers and Other Purposes. The LET examination for the elementary level includes the General Education (GE) courses and the Professional Education courses, while the examination for the secondary levels comprises three (3) components, general education, professional education, and field of specialization.

The examination consists of multiple-choice type of questions with four (4) alternatives that lasts from five and a half to nine hours. The elementary and secondary levels must attain an average rating of $75 \%$, with no rating of $50 \%$ or below in the component subjects. For the elementary level, $40 \%$ of the general rating comes from General Education, and $60 \%$ from the Professional Education. An average rating of $20 \%$ from the General Education, $40 \%$ from Professional Education, and $40 \%$ from Field of Specialization, for the Secondary level, (retrieved from PRC website).

\section{$>$ Experiences of the Passers and Non-Passers in the Licensure Examination for Teachers (LET)}

The National Academies of Sciences Engineering Medicine (NASEM) (2019) cited that the Internet is a highspeed electronic communication that links local, regional, and national networks. It allows individuals to access each other's computers for speedy communication or information retrieval. It means that students are no longer restricted from information, which was only supplied by textbooks and printed materials in libraries before. Students can "search" on the World Wide Web for articles on specific topics or topical compilations of materials for research.
As stated in the literature, most of the students prefer using search engines instead of e-libraries. However, Brophy and Bawden (2005) compared Google as an internet search engine with academic library resources in their study. Surprisingly, their finding proved that Google is superior for coverage and accessibility, while library systems are superior for quality of results. It means that accuracy is similar for both systems. Hence, it is essential to use them together for proper coverage because they have many unique items.

Further, the NASEM (2019) indicated that most web navigational software systems include search engines that allow the user to find information or sites by topic area. Surfing for information on the Web needs to be done carefully compared to a literature search for library references. The Web holds a massive probability in providing access to information. However, much of the information available may not have been reviewed for quality or reliability.

The study of Sahin et al. (2010) states that the Internet is a significant and indispensable source for students. With this, the issue of whether the referenced source is trustworthy and, or credible has also been raised. There is no control over any specific piece of information published through the Web, in opposition to the scientific and professional journals published by the scientific institutions, business world, and the organizations known to the public. Additionally, other journals and books issued by commercial organizations do not have a control unit, including editors and referees. Accordingly, many of the sites on the Internet enable anybody to submit any kind of information that does not undergo monitoring. Further, many of the sites known as reliable have restricted access for commercial purposes or security requirements (IP restriction, membership). Thus, this limits the accessibility of students and denies them of these sites.

Prior research ascertains that students could recall the main ideas despite the text type, but they could recall key points connected to the main idea and other relevant concepts when reading print better (Singer \& Alexander, 2016). Similarly, Jeong (2012) showed that higher quiz scores indicate better comprehension in print-based texts. Students also reported that eye fatigue and strain were more significant when reading e-texts. Further, Jabr (2013) asserted that eye fatigue causes decrease in concentration. It can also be a barrier to successful e-text-based learning, as screens strain the eyes and cause headaches.

There were various studies conducted on the relationship between academic achievements to the LET performance of the graduates in education. Pachejo and Allaga (2013) studied the academic predictors of the education graduates in Rizal Technological University in the LET performance. They established that there is a direct connection between the general LET scores and the three academic courses, such as general education, professional education courses, and specialization. 
Rabanal (2016) confirmed the findings in her study of the BEEd graduates in the University of Northern Philippines that achievements in the academic courses were significantly related to the various test components in the board examination. Contrarily, Garcia (2013) slightly deviated from the results mentioned above in professional education courses, which showed a weak positive correlation with LET performance.

Education plays a crucial function in the development of the Philippine educational system. The English language as the second language in the country is very significant in education to become globally competitive. It is one of the considerable factors needed to achieve better LET performance. San Miguel (2006) disclosed that schools deepen their efforts in training students to effectively use English in their academic work and everyday life. It means that the ability to communicate effectively does not only result to academic success but also translates into professional and career success.

The proficiency in academic language influences the LET performance. Zweirs (2004) explained academic language as the linguistic glue that holds the tanks, texts, and tests of school together. If students cannot use this glue well, their academic work is likely to fall apart. He further defined academic language as a set of words and phrases that describe the content-area, knowledge, and procedures. It expresses complex thinking process and abstract concepts and creates cohesion and clarity in written and oral discourse. Additionally, Krashen and Lee Brown (2006) described that academic proficiency consists of two components, namely the knowledge of the academic language and knowledge of academic content or specific subject matter.

There were already several studies undertaken by different TEI's in the country to improve the performance in the board examination. Quiambao et al. (2015) stressed that the teachers' educational attainment and length of service, the quality of library and laboratory facilities, the students' intelligence quotient (IQ) and grade point average (GPA) were a very significant set of predictors for passing the LET. Hence, these factors should be given considerations in developing policies for a better LET performance. However, the findings of Esmeralda and Espinosa (2015) in Carlos Hidalgo Memorial State College revealed that the BEEd showed greater confidence in academics, indicating the need to enhance the level of academic preparations of the BSEd in general education and significant subjects during preservice years.

Findings revealed that most of the respondents spent three to four months to review for their exam in terms of time management; in terms of memorization, mnemonics was standard among the respondents. It also disclosed that the majority took review sessions in private review centers. However, many considered group studies not useful compared to reading books and other references. Also, most of the respondents preferred a quiet environment during review and spent six to seven hours in rest and sleep.
Test-taking strategies are cognitive abilities that deal with any testing situations well independently of the knowledge of the test content. These are managing time effectively, surveying all questions before responding, dealing with difficult questions, dealing with multiplechoice questions, and underlying keywords questions (Dodeen, 2015).

Furthermore, these strategies aid students in deciphering their knowledge from classroom learning (McLellan \& Craig, 1989, as quoted by Dodeen, 2015). Hence, students who acquire test-taking strategies or skills progress in their academic performance, perk-up attitudes toward tests, lower test anxiety, and achieve better. Sweetnam (2003) emphasized that even students who are familiar with the subject matter may do poorly in tests because of a lack of test-taking skills.

However, today's teachers believe that drill-andpractice exercises on necessary skills are not as important as was previously thought. Drill and practice produce only rote memorization. It means doing something in a routine and responding automatically by memory without thought. The drill-and-practice exercises, if properly conducted, help students develop ease in the knowledge and skills they already understand (Heward, 2003).

Further, teachers deem drill and practice dull students' creativity, but leads to an increased competence and confidence with the subject matter or skills. Thereby, providing students with the knowledge and tools with which they can be creative. Brophy (1986), as cited by Heward (2003), concluded that the development of essential knowledge and skills necessitates large drill and practice to achieve automatic and faultless performance.

Swanson and Sachse-Lee (2000) conducted a metaanalysis on 85 academic intervention studies of students with learning disabilities. It revealed that the most substantial effect was on interventions that included regular drill, repetition, practice, and review. Also, it has shown that when properly conducted, drill and practice is consistently an effective teaching method.

Furthermore, a rapidly growing body of work suggests that time used in physical activity connects to a healthier body and mind (Hillman et al., 2008). It means that there is a relationship between exercise and mental health. In this regard, McGraw's (2006) deemed that regular physical activities are effective in decreasing anxiety and stress. Steptoe Cox (1998), De Geus (1993), Abbot et al. (1990), as cited by Nasiri (2015), affirmed that exercise and fitness and health programs are significant in maintaining good mental health.

Narimani (2000), Abolghasemi (2002), and McGraw (2000) proved that female athletes, who performed regular physical activity, were less anxious than female nonathletes. The higher mean of anxiety in the female nonathletes is evident in the present study, which is also consistent with the results of the investigation mentioned 
above. Boni (2004) agreed that a healthy cardiovascular system could be achieved by exercise.

Besides, Caviness (2009) described that the brain and body function as a data superhighway. The mind and body form a multifaceted system, like any other system, it must be appropriately developed and well maintained with proper nutrition. Hence, nutrition for both mental and physical health is exceedingly essential.

Consequently, Ross (2010) postulated that nutrition plays a vital role in proper physical and cognitive functioning. It affects energy levels, physical stamina, mood, memory, mental clarity, and emotional and mental well-being. Furthermore, Wolfe and Burkman (2000) claimed that diet, exercise, and sleep have the potential to alter brain health and mental function. Therefore, proper nutritional support is essential to allow the brain to function at its highest ability and to enhance learning. It shows the necessity to take adequate nutrients from food, or the body hampers learning.

Good nutrition affects the ability of the body to fight off diseases. Proper nutrition is more significant for those who have frail immune systems (Chung et al., 2006). Lahey and Rosen (2010) stressed that nutrition affected learning and behavior. They further emphasized that diet influence cognition and behavior in different ways.

A positively oriented individual possesses a general tendency to have a hopeful outlook (Alessandri, Caprara \& Tisak, 2012a). Also, positive orientation is a predispositional attribute, which consists three components, such as self-esteem, optimism, and life satisfaction as stated by Alessandri et al. (2012b).

Subsequently, self-esteem is an individuals' subjective evaluation of themselves, which can be both negative and positive (Baumeister, Campbell, Krueger \& Vohs, 2003). Optimism means looking at the future outcomes in life with a positive view. In contrast, pessimism is having a negative outlook on future outcomes (Eichner, Kwon \& Marcus, 2014). Conversely, life satisfaction refers to a subjective evaluation of how satisfied an individual is with life (Fredriksson \& Corméry, 2015). Positive orientation theory views self-esteem, optimism, and life satisfaction as a cognitive triad. It works as an inclination, intensifying wellbeing in everyday life (Alessandri et al., 2012a).

Alessandri et al., (2012) specified Beck's negative cognitive triad, which refers to a negative view of the self, the world, and the future. Negative thoughts cause someone to obtain feelings of depression that leads to dwindle wellbeing (Beck \& Alford, 2014). Contrarily, positive orientation is beneficial for subjective well-being (Caprara, Steca, Alessandri, Abela \& McWhinnie, 2010).

Generally, the role of positive orientation is for better handling and coping with stressful events (Alessandri et al., 2012a). Individual differences in test nervousness depend on how one handles it. If someone is positively oriented, he may feel less test anxiety and manage better with stress about exams.

The Philippines is the number one country in the world that believes in God the most. The Filipinos are like the Hebrews who have a powerful faith in God. The majority of Filipinos practice their faith in different ways. In the 16th century, the Spanish missionaries brought the Catholic Faith to the Philippines. From then on, Catholicism lingers as a fundamental part of the Philippine culture (Quintana, 2014).

According to Clemente et al. (2008), Maka-Diyos is a significant Filipino value. In 2001, a survey conducted in the Philippines by the World Values Survey and SWS asserted that Filipinos are religious people. The survey revealed that Filipinos believed in God; believe that people possess souls; get comfort and strength from religion; and consider God to be very important in their lives (World Values Survey, 2006).

Accordingly, Filipinos practice their belief through many significant events and spiritual devotions (Charentenay, 2020). The devotees' substantial commitment to particular holy rites is very significant. They believe that their real commitment is the condition for the answer to the grace or petition that guarantees a response from God.

Significantly, one of the rights of the learners is to receive relevant quality education primarily through competent instruction. Aljo and Tancinco (2016) mentioned various literatures to present substance and support on Faculty Performance and Students' Academic Achievement in the Licensure Examination for Teachers of Naval State University. He further indicated that college teaching should be handled by proficient teachers, who use a range of techniques and promote a positive climate for learning. Moreover, since the teaching skills required are developing, continuous professional development of teachers is imperative.

The students' achievement in the teaching and learning process is a result of the effort exerted by the teacher (Canlas, 2004). Therefore, the role of the teacher is held vital to teacher effectiveness that correlates to students' achievement. Thus, the quality of teaching performance as equated with teacher competence gauged on student achievement. However, Giglio (2009) pointed out that the teacher is an important determinant of the student's achievement, but there was no direct connection between the traditionally assumed measure of teacher effectiveness and student achievement over time. It encouraged them to develop other ways to improve teaching.

Wayne and Youngs (2002) revealed that parents, practitioners, and policymakers agree that the solution to improving education is positioning highly skilled and efficient teachers in the classrooms. It also proves that teachers need practical sets of standards and assessments to warrant that teachers are well prepared and ready to teach, especially the new ones. 
Further, Yarcia (2001) emphasized that the teacher is a part of the learning environment and that his teaching behavior affects the manner students observe the classroom climate. Although instructors cannot directly establish friendship and apparent climate among students, nevertheless teachers can offer a fundamental basis for a social experience.

Immediacy is often closely linked to credibility practices. It builds psychological closeness, or a connection between students and the teacher, which is part of the caring and character elements of teacher credibility (Teven \& Hanson, 2004). Further, Pogue and AhYun (2006) stressed that credibility and immediacy influenced student learning and motivation. Thus, teachers need to be both experts of content and to stimulate sincere interpersonal connections with their students. Catt, Miller, and Schallenkamp (2007) claimed that effective teachers have the ability to foster relationships and manage communication dynamics in the classroom.

Furthermore, Cadiz (2010) and Buenafe (2010), found out that the faculty in selected universities and colleges in Cordillera Administrative Region and Data Center College of the Philippines (DCCP) manifest an outstanding level of professionalism. These faculty showcased their rationality, responsibility, ethics, commitment, accountability, and creativity in their field of work. The level of performance of the faculty of DCCP is dependent on their professionalism. It proves that the students' performance in the examination is dependent on the teachers' performance.

According to the researches of Nyangena (2011) and Pascua et al. (2013), the students' performance in the licensure examination depends on the students' college academic achievement. It emphasizes the importance of the delivery of the curriculum to the students. It implies that dedication to effective and efficient instruction to facilitate students' academic achievement should be observed among all faculty members.

The undergraduate students enrolled in a teacher preparation program must prepare for licensure examinations in some way, as part of enrolment. The faculty members and preparation programs aid in preparing students for success on the examinations lead to passing licensure scores. Early exposure of students on test-taking strategies through forums, seminars, and classroom discussions shows to improve understanding of the test and succeed in the licensure exam. Childs, Ross and Jaciw (2002) also emphasized that the students' exposure to the test environment is beneficial to student success in a high-stakes testing environment

Besides, exposing students to testing objectives and time-management strategies has led to further success on high-stakes tests. Faculty members need to be proficient in the content knowledge to achieve students' passing licensure scores, as well as the assessment tool used to measure the student candidate preparation (Gulek, 2003).
The institutions devise mechanisms to identify and evaluate plans, programs, and activities to realize its commitment to quality education. The administration implements various means and supports for student learning, teaching, and learning environment, and teaching pedagogies.

Also, Miyasaka (2000) discovered that there is an increase in examination result by reviewing the test-taking strategies using the previous licensure examinations and holding content review sessions. He further suggested to make test-taking methodology as part of the college curriculum. Hence, students enrolled in the program generate a genuine and significant learning experience.

Similarly, studies looked into the training sessions on test-taking to find out if the programs on licensure examination results were effective. The method reviewed is translate, eliminate, solve or substitute, and tricks (TEST). Wall (2008) concluded that one's participation in the TEST program augments the teacher preparation examinations' scores. Wall, Johnson, and Seymonds (2012) revealed that introducing these strategies to students lessen nervousness in testing, while enhancing content knowledge and selfworth.

Moreover, other tutoring sessions prove to help prepare students to pass the examinations. In one study, Mee (2000) posited that there is provision of authentic test-taking environment and content anticipated to be on the examination for students. The experiences of the faculty members as test takers guided them in the grounding of the Praxis II content examination. The basis of the development of the program are the students' experiences. Hence, those students enrolled in the tutoring program had an $88 \%$ passing rate on the first try, compared to the $77 \%$ passing rate of those students who did not enroll in the program.

In another tutoring program for the Praxis I (LonwellGrice et al., 2013), pre-tests and post-tests determined the value of the tutoring sessions on student achievement. However, the use of one 45-minute tutoring session was useful only for those who had little to improve on. The tutoring sessions give limited information about student success on examinations and student participation.

Further, Visco (2015) stressed that review significantly influence the final licensure examination. Exposure to inhouse review or course audit is an essential preparation in taking the LET. Therefore, institutions are bound to provide a comprehensive course audit for their students.

Accordingly, the ineffective academic programs and in-house review implemented by the academe decreased the level of motivation of the student teachers to perceive better academic performance and high ratings of examination. Curriculum misalignment, including failure to fulfill educational training and mock examinations, were the problems encountered by the education graduates. Losing a quality educational system affects the academic, social, and pedagogical learning of the examinees. It could result in loss 
of motivation, interest, and determination in their examination (Pachejo \& Allaga, 2013).

Quiambao (2015), stressed that Mock Examinations or Comprehensive Examination conducted by the universities in the Philippines traced the weakness of the examinees and used to analyze their performance. The Bachelor of Science in Basic Education Graduates of the University of the Cordilleras underwent a LET mock examination. The College of Education Faculty established that the mock examination provided a positive impact to the students' performance. It is therefore, recommended to continually hold comprehensive or mock examinations for students before taking the Licensure Examination for Teachers to increase their probability of passing the board examination.

Also, the administration provided support to the teaching and learning environment. The school facilities are one of the essential factors for quality education. These include school building, library, laboratory, textbooks, software and hardware of educational technology, and others. Adequate school facilities aid students' learning outcomes and achievement.

Omotunmise and Fredrick (n.d.) recognized that facilities constitute a strategic factor in any organizational functioning. He further stated that facilities are a major contributing factor to academic achievement, efficiency, and high productivity among students. A positive relationship exists between the availability, adequacy, and relevance of facilities and students' academic achievement as they can enhance the active teaching-learning process.

According to Building Educational Success Together (BEST, 2005), it is the responsibility of every administrator to ensure that every child has access to quality education. They need to provide an educational setting suitable for teaching and learning. Also, it is necessary to implement educational policies that result in high quality performance. Well planned and maintained school facilities can directly or indirectly impact the teaching and learning process. Effective facilities management, therefore, contributes to the success of every student in any school.

Onwurah (2004) stressed that the school facilities play a critical function in the development of the three domains of Bloom's Taxonomy of educational objectives, namely; cognitive, affective, and psychomotor. Educational facilities developed the cognitive area of knowledge, abilities, and skill, which are qualifications for academic achievement. School facilities comprise of the school land and all the physical structures like the school building, the playgrounds, the equipment, and other material resources provided in the school for effective teaching and learning operations (Onuorah, 2004). Moreover, Afolabi (2002) concurred with Onwurah (2004) about the definition and importance of school facilities, which contribute to a positive learning environment and quality education for all students. Afolabi (2002) further stressed that the learning facilities available within an educational institution have a positive relationship with the quality of teaching and learning activities to attain the goals set.

Many educational administrators and planners highlighted the significance of school facilities. It is a means for effective teaching and learning (Saiyida \& Sidhu, 2012). Similarly, Kocheny (2012) asserts that school facilities are vital factors to the enrolment of students in the school. He further observes that through ample planning of school facilities, they can determine the type of instructional materials teachers would need for effective instructions.

In the view of Wright, Horn, and Sander (2007), teachers play a crucial role in education, for they influence student learning. The teacher is the interface of the transmission of knowledge, values, and skills in the learning process. Students may have little progress academically if the teacher is ineffective.

Teacher qualifications also affect the teaching and learning process as well as the student's academic performance. Afe (2001) discoursed that whatever the profession, there is a need for training to create awareness and advance profession, he further stressed that would improve the level of competence.

The Commission on Higher Education (CHED) prescribes the system of regulation, policies, standards, procedures, criteria, and guidelines on the implementation of the reviews to the graduates of the Higher Education Institutions (HEIs). The standard was under the provisions of Republic Act No. 7722 or the Higher Education Act of 1994 and Executive Order 566

Moreover, the CHED should adopt a policy to preserve the right of the enrolees to any review centers that provide quality outcomes and services in the licensure examinations. It may avoid the deterioration of quality services and unethical practices which are detrimental to the enrollees in these review centers. The HEIs have academic freedom where they are allowed to include or integrate into their curriculum review subjects with the corresponding credits as a requirement for graduation.

One of the significant concerns that the review centers must consider is the availability and adequacy of highly and ethically qualified experts. The qualifications of the reviewers, mentors, and teaching coaches is a master's degree or at least five (5) years teaching experience or as a reviewer. It ensures the review centers' quality reputation and integrity.

Social support is one's perceptions of supportive behaviors from individuals in a social network, specifically parents, teachers, classmates, close friends, and school. Closer relationships tend to create a more expensive types of support than casual acquaintances and offer more specialized support. The sources and types of support are interconnected. The closer the relationship, the higher the correlation among the several types of support (Gottlieb \& Bergen, 2010). 
Besides, close ties with partners and other nuclear family members provide bonding to show support such as listening, caregiving, and affection. The more distant, roledefined ties provide bridging, specializing in practical assistance and a variety of new information and advice (Wuthnow, 2002). The support from family and friends reduce the students' psychological problems (Calvete \& Connor-Smith, 2006). Also, Villanova and Bownas (1984) asserted that students cope with daily life pressure and lessen the load of academic workload. But they are susceptible to depression, stress, and anxiety without enough support from family and friends.

Rosenfeld, Richman, and Bowen (2000) established that students with tremendous support from parents, teachers, and friends had better grades compared to students without support. It indicates a relationship between social support and GPA. However, some factors influence the relationship between social support and academic performance.

Furthermore, social support provides for the successful management of stress and stressful events. It has positive effects on both the mind and body and contributes to successful stress management. It also reduces psychological distress and promotes adjustments that counteract highstress levels. People with little quantity of social support accounts for higher instances of depression, anxiety, and mental disorders. For these people, stressful situations create higher amounts of panic, phobia, and disorder than for those with high social support. Social support also bolsters physical health, which can counteract many adverse effects of stress (Boundless Psychology, 2012).

Social support depicts psychological, physical, and financial supports accessible and available in times of need to give to an individual through social ties or a network of family, friends, neighbors, and community members. It has been explored how social support may enhance mental and physical health. Individuals with rich social networks use active coping mechanisms when dealing with stressful life situations (Ozbay et al., 2007).

Social support acts as a protective factor, which decreases psychological problems among students, such as stress. This finding was supported by Dollete et al. (2004) that Wentzel (1998) also confirmed that social support provides a motivational influence on students' performance. Further, Quomma and Greenberg (1994) supported the findings that less social support leads to failure.

Furthermore, Nahid and Sarkis (1994) clarified that high level of anxiety, stress, and depression of college students result from low levels of support. Social support is one of the most crucial protective factors for students (Tao, Dong, Pratt, Hunsberger, \& Pancer, 2000).

Sources of support increase the possibility that an individual will depend on active problem solving and information seeking. These help students deal with different stressors and assist a positive adjustment process. The support provided buffer the influence of stress by amplifying the coping efforts, which also decreases misery among students (Holahan et al., 1995; Lakey \& Cohen, 2000).

In effect, the professors who provide a supportive and encouraging environment help students to uphold the motivation to realize success. Students also seek the advice of their peers concerning teacher licensure test-taking strategies. Students who acknowledge their learning needs and seek support from trusted peers resulted in passing the examination. Seminars on test preparations have also contributed to exam persistence and success (Baker-Doyle \& Petchauer, 2015).

The literature and studies mentioned above have provided insights into the present study. It gave the researcher a clear understanding of the experiences of the passers and non-passers in the Licensure Examination for Teachers. Further, it also elucidates several contributory factors of the future teachers' LET performance. Examples of these factors are self-related factors such as selfpreparation, well-being, and self-efficacy. It also clarifies that the instructors' teaching effectiveness is not the only measure of credibility, but the character traits, and a loving relationship with the students.

The theory of social support made the researcher realize its valuable impact on the performance of the LETtakers. These supports are in varied forms coming from the administration, family, and other stakeholders. Furthermore, the law on the implementation of the review reinforced the findings of the study. It highlights the provision and protection of the rights of the enrollees on quality review sessions. Finally, several related studies were cited that confirm and negate the findings of the present study.

\section{METHODOLOGY}

\section{$>$ Research Locale}

This study was conducted at Bukidnon State University (BukSU) located in the heart of Malaybalay City, Bukidnon, Philippines. BukSU is known for its mission to develop competitive professionals and committed to providing excellent instruction. The university has six colleges, one of which is the College of Education. It offers Bachelor in Elementary Education (BEE), Bachelor in Secondary Education (BSE), Bachelor in Early Childhood Education (BECE), and Bachelor in Physical EducationSchool of Physical Education (BPE-SPE) respectively. The Elementary Laboratory School (ELS) and Secondary Laboratory School (SLS) catered these students during their Field Study and Student Internship courses. Their pedagogical content knowledge and skills that they learned in their general education, professional education, and specialization courses are being applied and homed in the laboratories under the supervision of the Supervising Instructors. 


\section{$>$ Participants of the Study}

There were a total of 36 participants of the study consist of 18 passers and 18 non-passers who were purposively chosen and took the LET during the years 20162018. They were from the main campus, external centers, and Certificate of Teaching LET-takers who took 18-unit Professional Education subjects.

\section{> Data Gathering Tools}

There were two (2) researcher- made instruments used in the study such as interview guide questions for the semistructured interview and motive questions for the focus group discussion. Panel of experts validated the instruments to ensure that they capture significant statements from the participants. At times, the researcher used additional followup or probing questions to clarify or expand the participants' responses.

\section{$>$ Data Gathering Procedure}

The researcher secured a letter of recommendation from the Dean of the College of Education of Bukidnon State University addressed to the university president for approval. The researcher personally conducted the interviews to the participants and followed the ethical processes. This was done in a place conducive for the participants to freely express their thoughts, feelings, and experiences on Licensure Examination for Teachers (LET) as passers or non-passers.

\section{Data Analysis}

The phenomenological process in data analysis of Colaizzi (1978) as cited by Morrow and King (2015) was used by the researcher following the processes: (1) the reading and re-reading of the transcribed interviews shared by the participants; (2) the extraction of significant statements from the transcript; (3) the formulation of meanings on every significant statement after re-reading thoroughly the transcription; (4) the formulated meaning was analyzed to determine and group its theme cluster and emergent theme; (5) the identified emergent themes were exhaustively defined and described, as uncovered the phenomenon in the study; (6) the findings of the study were validated by the participants to compare the descriptive results constructed by the researcher with their experiences and as a result, have finalized the descriptions of the phenomenon.

\section{$>$ Ethical Considerations}

The researcher followed proper protocol in gathering the data. A letter of recommendation was secured from the Dean of the College of Education of Bukidnon State University addressed to the participants of the study. Then, the researcher met the participants and set the schedule in the conduct of the study at a convenient time. In addition, the researcher requested the participants to sign the written informed consent before the conduct of the study. confirm that you have the correct template for your paper size. This template has been tailored for output on the A4 paper size. If you are using US letter-sized paper, please close this file and download the file "MSW_USltr_format".

\section{RESULTS AND DISCUSSION}

$>$ Experiences of the Passers and Non-Passers in the Licensure Examination for Teachers (LET) as LET-taker Emergent Theme 1: Engaging to Self-directed Undertakings

The LET-takers both the passers and non-passers carried out self-directed efforts in preparation for the LET. Through the significant statements that the participants shared during the interviews, engaging to self-directed undertakings emerged as a theme. There were four (4) subthemes yielded from the emergent theme; these were acquisition of resources, taking responsibilities, applying acquired competencies and study techniques, and conditioning the self.

\section{- Sub-theme 1: Acquisition of Resources}

The passer and non-passer participants did several means of acquiring resources for review and to equip themselves with the competencies they needed for the LET exam. True to all the groups, the most accessible means of securing review materials is through the online sources. It has become a trend globally; however, the participants did not screen the reliability of the sources or websites of the materials they have downloaded. The evaluation of the sources and quality of the acquired information from the internet is necessary.

In line with the National Academies of Sciences Engineering Medicine (2019), the internet is an international high-speed electronic communications network links which allow individuals to rapid access and retrieval of information but much of the information available has not been reviewed for quality or reliability. Sahin et al. (2010), there is no control on any information published through the web unlike the scientific and professional journals published by the scientific institutions known to the public. Brophy and Bawden (2005) compared Google as an internet search engine having superior coverage and accessibility while academic library resources are superior for quality of results; precision is similar for both systems.

The LET-takers also used compiled questionnaires obtained from the review sessions; however, it was noted that unlike the non-passers group, most of the passers used reliable and updated printed review materials like books published by known authors. In addition, some passerparticipants preferred visual processing such as reading and making textbooks as very effective resources. This basic finding is consistent with the research of Singer and Alexander (2016) showing that it is better to recall key points and other relevant concepts when reading in print. Jeong (2012) that better comprehension can be achieved in print-based texts. In comparison, reading e-texts, which cause eye fatigue and strain, may affect better performance. Moreover, decreased concentration caused by eye fatigue can be a barrier to successful e-text-based learning, as screens can strain the eyes and cause headaches (Jabr, 2013). 


\section{- Sub-theme 2: Taking Responsibilities}

Some passers and non-passers in LET exhibited the sense of responsibility or accountability in preparation for the LET. All the participants from the passers and the nonpassers groups attended their classes regularly. They accomplished their tasks and complied with the requirements that were expected of them as students. They all yearned to pass and be successful in LET and extended efforts in the preparations. It is interesting to note that the passers group had set their goal, maintained high grades, determined, and persistent towards passing the LET. In addition, they clarified concepts and ideas to their instructors as the appropriate person who could shed light if they experienced misunderstandings to concepts and ideas.

This analysis confirmed the findings of Pachejo and Allaga (2013), in their study regarding academic predictors in LET performance of education graduates in Rizal Technological University. It found the linear relationship between the overall LET ratings and the performance of the LET-takers in academic courses. Rabanal (2016) strengthened these findings by analyzing the performance of BEEd graduates in the University of Northern Philippines. Her study revealed that academic achievements in academic courses were significantly related to the different test components in the board examination. The findings of Garcia (2013) deviated slightly from those mentioned above in professional education courses where it noted a weak positive correlation with LET performance.

For the non-passers, there were some important differences with the passers that were evident. They experienced difficulties in understanding the English language and the theories. The inability to comprehend with the English language leads to the lack of ability to grasp the theories in education. This result ties well with the study of San Miguel (2006), which emphasized that the use of English language in the academic work and the ability to communicate effectively are not only essential to academic success; it translates directly into professional and career success. Likewise, Zweirs (2004) associated academic language as the linguistic glue that holds the tanks, texts, and tests of school together. If students cannot use this glue well, their academic work is likely to fall apart. To obtain academic proficiency, it is essential to have the knowledge on academic language and knowledge on academic content or specialized subject matter (Krashen \& Lee Brown, 2006).

Moreover, the non-passers also expressed their difficulty in the retention of learning and lack of focus in academic responsibilities, divided focus between academic and non-academic tasks, and inadequate preparation on his academic. Quiambao, Baking, Buenviaje, Nuqui, and Cruz, (2015), one of the very significant set of predictors for passing LET were students' intelligence quotient (IQ) and grade point average (GPA). The findings of Esmeralda and Espinosa (2015) in Carlos Hidalgo Memorial State College indicated the need to enhance the level of academic preparations in general education and major subjects to perform better in LET.
- Sub-theme 3: Applying Acquired Competencies and Study Techniques

It was evident in the passer groups that varied test taking skills and strategies were utilized even before in preparation for the LET exam. They used drill exercises; they repeatedly answered the questionnaires for familiarizations and sometimes lead to memorization of the concepts and theories. However, among the non-passers group, only one participant has mentioned on the use of strategies during the LET review. The strategies in testtaking help the LET-takers deal with the challenges of the examinations. It eased their test anxieties because of their ability to work well independently on the knowledge of the test content.

This analysis found evidence in Heward (2003) that development of basic knowledge and skills to the necessary levels of automatic and errorless performance require a great deal of drill and practice. In addition, Swanson and SachseLee (2000) point out that drill and practice is a consistently effective teaching method when properly conducted. A similar pattern of result was obtained by Heward (2003) that drill-and-practice exercises if properly conducted help students develop fluency in the knowledge and skills they already understand. Dodeen (2015) identified indicators of developed test taking strategies like managing time effectively, surveying all questions before responding, dealing with difficult questions, dealing with multiplechoice questions, and underlying keyword questions. He also claims that students who have developed test-taking strategies or skills will positively affect their testing competency. Sweetnam (2003) supported the findings that even students who are familiar with the subject matter may do poorly in tests because of the lack of test-taking skills.

\section{- Sub-theme 4: Conditioning the Self}

As noted in the passers groups, more were mentioned for the physical preparations compared to the non-passers groups. Further, there was also the difference in the consistency of the preparations of the two groups. The passers group showed to have prepared physically more regularly. The results led to similar conclusion of Hillman et al. (2008), time spent or engaged in physical activity is related not only to a healthier body but also to a healthier mind. It also stimulates brain function and cognition and may decrease anxieties and worries brought about by the upcoming LET. This result ties well with previous studies cited by Nasiri (2015) and McGraw (2006) wherein regular physical activities are effective in reducing anxiety and stress. Boni (2004) also believes that good psychological mood can be achieved by exercise.

The passers groups were more particular on having healthy diet and well-balanced meals. On the contrary, most of the participants from the non-passers groups indicated no change in their usual diet. Wolfe and Burkman (2000) that diet, exercise, and sleep have the potential to alter brain health and mental function. With proper nutritional support, it allows the brain to function at its highest ability and to enhance learning. Likewise, Caviness (2009) revealed the effect that nutrition has upon both mental and physical 
health is exceedingly important. Ross (2010) also postulated that nutrition affects energy levels, physical stamina, mood, memory, mental clarity, and emotional and mental well-being. This finding was confirmed by Lahey and Rosen (2010), nutrition affects cognition and behavior in many ways, which include the condition of not having enough nutrition or the condition of the lack of certain nutrients, while Chung et al. (2006) emphasized that nutrition influences the body's ability to fight off illnesses.

The passers and non-passers were firm not to entertain problems during their reviews to refrain from getting stressed and worried. They uphold positivity and optimism, life-study balanced, psychological readiness, have someone as inspiration, maintain confidence, and self-trust. It can be observed from the non-passers groups to have tried to avoid stress despite their problems. However, there were some mixed feelings of having self-doubts, discouragement, inability to focus due to pressures, and feeling hopeful but complacent. The present findings confirmed Alessandri, Caprara, and Tisak' (2012) assertion that an individual who is positively oriented has a tendency to have a positive outlook in life. In addition, positive orientation is beneficial for subjective well-being (Caprara, Steca, Alessandri, Abela \& McWhinnie, 2010); and it contributes in handling and coping better with stressful events (Alessandri et al., 2012a). An individual with a positive predisposition may experience less test anxiety because of more positive cognitions and coping better with stress in relation to exams. In contrast, an individual who possess negative thoughts is prone to develop feelings of depression, which in turn leads to decreased well-being (Beck \& Alford, 2014).

According to the participants, the most important aspect that every LET-taker would never forget is to seek God's intervention. Most of the participants, sought spiritual guidance, sustained devotions, and prayer support. They believed that praying reduced the stress, nervousness, and pressures. They also assumed that in God's perfect time and by His grace and blessings, they will pass the LET. The responses of all the groups both the passers and non-passers revealed the strong faith and belief in God. According to Quintana (2014) in his article on Filipino Faith in God Likens to the Hebrews, Filipinos have a very strong Faith in God. It remained an integral part of the Filipinos' culture and way of life.

Likewise, Clemente et al. (2008) on his study on Revisiting the Kapwa Theory: Applying Alternative Methodologies and Gaining New Insights described Filipinos of having high regards in religion and being makaDiyos The assertion that Filipinos are religious people was also supported by the World Values Survey (2006) conducted in the Philippines. The survey revealed that Filipinos believed in God, get comfort and strength from religion, and consider God to be very important in their lives. Further, Charentenay (2020) indicated that Filipinos practiced one's own belief through spiritual devotions, which involves the devotees' physical commitment. They believe that their physical commitment is the condition for the answer to the grace or petition that the devotee has been asking.

\section{$>$ Experiences of the Passers and Non-Passers in the Licensure Examination for Teachers (LET) with the Instructors}

Emergent Theme 2: Demonstrating Teaching Credibility

As experienced by the LET-takers, different levels of credibility were observed with their instructors that contribute to their LET performance. The emergent theme emerged was the demonstration of the teaching credibility. From the emergent theme, it generated two (2) sub-themes such as instructors' teaching competence and character traits and the use of appropriate teaching strategies, medium of instruction, and assessment practices.

\section{- Sub-theme 1: Instructors' Teaching Competence and Character Traits}

In general, the instructors' teaching competence and character traits were described differently by the participants based on their experiences with them. The LET-takers were taught by instructors who have varied level of teaching competence based on their teaching experience. The participants from both the passer and the non-passers groups claimed that the more experienced the instructors in teaching, the more competent they were in their teaching performance.

Every student has the right to quality education through competent instruction. Wayne and Youngs (2002), highly skilled and effective teachers are the key to improve education. The study of Aljo and Tancinco (2016) on Faculty Performance and Students' Academic Achievement in LET, that college teaching should be taught by competent teachers, who use various techniques and fosters positive climate for learning. Canlas (2004) emphasized that teachers' effectiveness correlates to students' achievement. It has always been regarded as the result of the effort exerted by the teacher in the teaching and learning process. However, Giglio (2009) disproves the claim of Canlas (2004), he pointed out in his study on the relationship between teacher quality and student achievement that there was no direct connection between the traditionally assumed measure of teacher effectiveness and student achievement over time. It encouraged them to develop other ways to improve teaching.

There were also some instructors who were observed to have remarkable commitment to teaching. Some participants had been provided with extra help and time by their instructors beyond their duty and with additional support through mentoring. Further, particularly from the passers groups, the willingness of some instructors to offer additional support to students provided an avenue for the learning needs and difficulties of students to be catered.

It was pointed out by Yarcia (2001) that the teacher's teaching behavior affects the manner by which students perceive the classroom climate where the instructors may offer a vital firm base for social experience. Likewise, Pogue and AhYun (2006) and Teven and Hanson (2004) 
linked non-verbal immediacy to credibility practices. They found out that both credibility and immediacy significantly influenced student learning and motivation. The teachers are expected to be both experts of content and to engender sincere interpersonal connections with their students. In the same manner, Catt, Miller, and Schallenkamp (2007), the most effective teachers are not only masters of content, but also have the ability to foster relationships and manage communication dynamics in the classroom.

Further, the level of performance of the faculty is dependent on their professionalism. The higher the level of professionalism of the faculty, the higher is the performance of the students in examination. These include the teachers' rationality, responsibility, ethics, commitment, accountability, and creativity according to Cadiz and Buenafe (2010). The researches of Nyangena (2011) and Pascua et al. (2013), emphasized the importance of the delivery of the curriculum to the students, which implies that commitment to effective and efficient instruction to facilitate students' academic achievement should be observed among all faculty members.

- Sub-theme 2: Use of Appropriate Teaching Strategies, Medium of Instruction, and Assessment Practices

The connection between what is taught and how it is taught is very significant in order to maximize student learning. Based from the responses, all the participants had experienced the different teaching strategies as students. They expressed how their instructors used appropriate teaching strategies, medium of instruction, and assessment practices. Most of the participants were exposed to different teaching strategies appropriate to their needs such as experiential, self-regulated, and collaborative learning strategies, feed backing, and reporting. Moreover, a few instructors provided LET-patterned examinations as assessment tools that enhanced test taking skills. However, as observed, proficiency in the use of language in teaching, embedding practical applications to learning, and relating to actual situations in teaching were highlighted. It was revealed that there were participants who experienced limited understanding on theories and principles due to English language constraints by certain instructors.

As highlighted, the learning needs of students have to be prioritized in the use of different teaching strategies and assessment tools. The findings of Childs, Ross and Jaciw (2002) suggested that the instructors can help students prepare for success on the examinations through teaching them the needed competencies for the test and test-taking strategies may it be in a form of forums, workshops, and regular classroom discussions. Likewise, exposing students to testing objectives and time-management strategies has led them to further success on high-stakes tests. Gulek (2003) stressed that instructors who are preparing students to achieve passing licensure scores must also be proficient in the content knowledge that will be assessed, as well as the assessment tool used to measure teacher candidate preparation.
$>$ Experiences of the Passers and Non-Passers in the Licensure Examination for Teachers (LET) with the Administration

Emergent Theme 3: Institutional Commitment for Quality Education

The participants experienced varied supports provided by the administration, may they be in the main campus, external centers, and CT graduates. The emergent theme developed from the LET-takers experiences with the administration in preparation for the LET examination was the institutional commitment for quality education. From the emergent theme which emerged based on the experiences of both the passers and non-passers in LET, it generated three (3) sub- themes such as support to student learning, support to teaching and learning environment, and support to pedagogy.

\section{- Sub Theme 1: Support to Student Learning}

The BukSU is committed to deliver quality education to the students. These were demonstrated by extending support for student learning. It was shared by all the participants from both the passer and non-passer groups that there were various initiatives that the administration particularly the COE have conducted in preparation for the LET. The administration outsourced credible experts from other prominent universities and review centers to enhance the LET performance of the graduates. They also conducted intensive review sessions but limited only to the main campus and offered supplemental subjects like ED 139 and 140. The English Intensive Training, pre-board exam, and mock exam were also conducted where the participants found them very helpful.

It was presented by Miyasaka (2000) that allowing teacher candidates to review test-taking strategies, holding content review sessions, and embedding in the curriculum the test-taking methodology have shown to increase success on examinations. In one study performed by Wall (2008), the conduct of test-taking tutoring sessions increased scores on teacher preparation examinations. Wall, Johnson, and Seymonds (2012) presented translate, eliminate, solve or substitute, and tricks as T.E.S.T strategies to students that helped them reduce testing anxiety while increasing content knowledge and self-efficacy. In one study, Mee (2000) posited that providing students with an authentic content and test-taking environment had a higher chance of passing rate.

In another tutoring program as proposed by LonwellGrice et al. (2013), the use of pre- and post-test evaluations was an effective measure of student success and the use of one 45-minute tutoring session proved to be useful for only the students who had little to improve on. Further, Visco (2015) posed that licensure examination review also has a significant influence on LET which means that exposure to in-house review or course audit is also essential preparation for taking the LET. On the other hand, institutions are bound to provide a comprehensive course audit for their students. 
In relation to advocating licensure examinations' effectiveness, Quiambao (2015) revealed that mock examinations or comprehensive examination conducted by the universities in the Philippines traced the weakness of the examinees and have analyzed their performance. Through undergoing mock examination in the L.E.T. and imitating the actual examination, it was found out that respondents gained positive impact in their LET performance. It was also revealed by Pachejo and Allaga (2013) that losing the quality of educational system, ineffective academic programs and in-house review, curriculum misalignment including failure to fulfill educational training and mock examinations can largely affect the academic, social and pedagogical learning of the examinees. These result to loss of motivation, interest, and determination in the examination.

\section{- Sub-theme 2: Support to Teaching and Learning Environment}

The administration was also committed to give support to teaching and learning environment. This was experienced by the participants through the approval of policies relevant to LET such as enhancement program, pre-board examination, final coaching, and the additional subjects like Ed 139 and 140 which could contribute to the improved performance in LET of the graduates. According to Building Educational Success Together (BEST, 2005), implementing educational policies that resulted in high quality, high performance, and well designed and maintained school facilities had a direct and indirect impact on the teaching and learning process.

Also, the participants have expressed that they were extended with quality and equipped school facilities by the administration which helped them prepare for the LET. These were computer laboratories, university library equipped with books and with free internet connections. The findings of the study have similar pattern of result from various studies. The availability, adequacy, and relevance of the school facilities impact efficiency, high productivity, and academic achievement among students as they can enhance effective teaching and learning process (Omotunmise \& Fredrick, 2016; Onuorah, 2004). Furthermore, Onwurah (2004) stated that the school facilities play a crucial role in the development of the cognitive area of knowledge, abilities and skill, which are prerequisites for academic achievement.

\section{- Sub-theme 3: Support to Pedagogy}

In order for the university to provide quality education, the qualifications for the hiring of teachers are strictly considered to ensure taking in proficient and competent instructors. In support for LET, the instructors were also sent to trainings and seminars to be abreast with the latest trends in teaching pedagogies, necessary for handling LET reviews. Similarly, the rest of the participants from the passers and non-passers groups generally expressed that they have competent instructors who also attended different trainings and seminars for professional growth. The commitment of the university in the delivery of quality education through its competent instructors is to be complemented with the students' interest and willingness to learn. It implies the collaborative efforts of the administration, instructors, and the students to achieve the goals.

Wright, Horn and Sander (1997) viewed teachers as the most important factor that influence student learning. They interface the transmission of knowledge, values, and skills in the learning process. Regardless of the students' individual capability, the teacher may affect the students' progress or academic achievement. In addition, the teacher's qualification affects the teaching and learning process and the student's academic performance. They need constant training to create awareness and advance profession. He further stressed that such training would improve the level of teacher's competence (Afe, 2001).

\section{Experiences of the Passers and Non-Passers in the Licensure Examination for Teachers (LET) with the Family}

Emergent Theme 5: Imparting Kin-based Social Support

The LET-taker passer and non-passer-participants received support from their family members. The emergent theme from the LET-takers' experiences with their family in preparation for the LET examination was imparting kinbased social support. From the emergent theme, providing multi-faceted forms of support yielded as sub- theme.

\section{- Sub Theme 1: Providing Multi-faceted Forms of Support}

The Filipinos are known to have close family ties. The close ties with the family members provide bonding and intimate expressions of support, may it be tangible or intangible. These supports were unconditional wherein only the members of the family could provide. Both the passers and non-passers were provided with multi-faceted forms of support in preparation for LET. These were emotional supports like comforting words, moral and spiritual support, warmth, and care. Additionally, they were also provided with esteem support such as motivation, re-assurance, and encouragement and instrumental support like the provision of financial assistance. The participants considered these supports as very important and helpful to them in facing the challenges of the LET.

Moreover, the varied support coming from the loved ones were found to be an essential factor not just in passing the LET, but most of all for the non-passers not to give up. The support helped them to regain back their confidence, determination, and motivation to try harder the next time. Social support is one's perceptions of supportive behaviors from individuals in a social network like parents.

It has been found that the closer the relationship, the greater the correlation among the several types of support. People, we feel close to are perceived to be repositories of all types of support (Gottlieb \& Bergen, 2010). In addition, as stated in Boundless Psychology (2012), social support provides successful management of stress. It has positive effects on both the mind and body and reduces psychological distress. It was postulated that people with low amounts of social support reported to have higher 
instances of depression, anxiety, and mental disorders than those with high social support. Further, the result of the study affirmed the findings of Rosenfeld, Richman, and Bowen (2000) that students with high level of support from parents had better grades compared to students without such support. However, there may be other factors to consider wherein social support may be related to academic performance for some students but not for others.

$>$ Experiences of the Passers and Non-Passers in the Licensure Examination for Teachers (LET) with the Resource Persons

Emergent Theme 5: Exhibiting Capability and Quality

The resource persons were the pool of experts of the university, invited speakers from prominent universities and review centers, and topnotchers in LET from the previous years. From their experiences, exhibiting capability and quality emerged as a theme whereas; the credibility of the human resource came out as the sub-theme.

\section{- Sub Theme 1: Credibility of Human Resource}

In the implementation of the review sessions, there were provisions established by the CHED to ensure its quality and to provide the enrolees with the competencies required for the LET. The BukSU, as one of the implementers of the review sessions have complied with the provisions of CHED. There were adequate numbers of invited qualified resource persons from the university, from other prestigious university, and review centers.

All the passers and the non-passers from the main campus attested on the credibility, expertise, and integrity of the resource persons. They introduced test taking strategies like, rationalization, identifying key words context clues, and simplifying complex ideas. Moreover, the resource persons presented and highlighted latest trends, current issues, and evolving concepts. However, the participants experienced limited time with the experts. However, for the external centers and the CT groups for both the passers and the non-passers, it was observed that not all attended the review sessions. However, those who enrolled at the review centers, they also conveyed that it was a productive review because of the credibility of the resource persons. The utmost response was on the use of test-taking skills, which the application greatly depended on the ability of the testtakers.

The Commission on Higher Education (CHED) was directed to prescribe the system of regulation, policies, standards, procedures, criteria, and guidelines on the implementation of the reviews. It adopts a policy to preserve and protect the right of the enrollees they may be provided with quality services and outcomes in the LET. Pursuant to Executive Order 566 on the Implementing Rules and Regulations Governing the Establishment and Operation of Review Centers and similar entities in the Philippines, the review centers must consider the availability and adequacy of highly and ethical qualified experts. They should have at least a master's degree or have at least five (5) years teaching professional experience or as a reviewer to ensure quality reputations, and integrity of the review centers (CMO 30, series of 2007).

$>$ Experiences of the Passers and Non-Passers in the Licensure Examination for Teachers (LET) with the Other Stakeholders

Emergent Theme 6: Extending Non-Kin Based Social Support

The emergent theme appeared from the experiences of the participants was extending non-kin based social support while the sub-theme was the multi-dimensional forms of support. These supports were esteem, emotional, informational, and instrumental.

\section{- Sub Theme 1: Multi-dimensional Forms of Support}

Based on the responses, all the groups received social support coming from their friends, colleagues, co-workers, and instructors which they considered very much important in their journey during LET. These supports were in the form of tangible assistance like review materials and financial assistance from the barangay, appraisal, effective coping strategies, prayers, advice, and practical test-taking tips, and emotional. It helped them reduced the amount of stress they experienced, elevated their confidence during the exam and helped them cope better in dealing with stressful situations. In the case of the non-passers, it also lifted their morale despite their failure and helped them to remain positive.

Support from family and friends have been found to reduce the impact of psychological problems among students (Calvete \& Connor-Smith, 2006). It was found out that it could help students to cope with everyday life stressor and lighten the burden of academic workload. This finding was supported by Dollete et al. (2004) who found that social support could act as a protective factor that could decrease psychological problems such as stress. It provides motivational influence on students' performance; however, less social support would lead to failure. Lack of support from friends and other persons may cause depression, stress and anxiety. (Tao et al., 2000).

Advice and encouragement from sources of support may also increase the likelihood that an individual will rely on active problem solving, information seeking, deal positively with various stressors. (Lakey \& Cohen, 2000). Further, it was emphasized by Baker-Doyle and Petchauer (2015) that the instructors who provide a supportive and encouraging environment can help students to maintain motivation and achieve academic success.

\footnotetext{
$>$ A Proposed Action Plan to Enhance the Performance in the Licensure Examination for Teachers (LET)

The action plan was designed to address the areas of concern by the non-passers in the Licensure Examination for Teachers (LET). This action plan is deemed necessary because it will serve as a guide that provides different productive activities, which would help the non-passers as well as the education students, instructors, administration specifically the COE realizes its goal of maintaining the
} 
increasing passing rate of the university and in pursuit of excellence.

It aimed to (1) to continuously advance the teaching performance of the instructors by providing them continuing professional development that would strengthen and enhance their teaching strategies and mode of assessment patterned to LET, and be updated with evolving concepts and theories in education (instruction); (2) to conceptualize an assessment tool that would be used as an evaluation mechanism to all the activities employed for LET (research); (3) to formulate an extension program that would address the needs of the non-passers and decrease the numbers of non-passers (extension); and (4) to develop updated and aligned resource materials from the Table of Specifications (TOS) published by the Philippine Regulation Commission (PRC) (production).

\section{ACKNOWLEDGMENT}

The researcher expresses her gratitude to Almighty God and to the following persons who helped much for the success of this study:

Dr. Oscar B. Cabañelez, President, Bukidnon State University (BukSU), for his support in the Graduate Programs and for his encouragement and providing the BukSU faculty members the opportunity to enhance their professional growth and development.

Dr. Estela C. Itaas, (former VPAA) for her motivation, wisdom, and brilliant ideas and Dr. Hazel Jean M. Abejuela, Vice President for Academic Affairs (VPAA) being supportive of the Graduate Program.

Dr. Zita I. Dales, my compassionate dissertation adviser who never failed to extend her time, guidance, and valuable ideas and for giving the all-out support in the accomplishment of this paper.

Dr. Mercidita S. Villamayor, Dr. Susan S. Olana, Dr. Elvira B. Sumbalan, and Dr. Reynaldo T. Oton, the dissertation committee, for their inspiring words, constructive suggestions, and valuable ideas that helped the researcher a lot in the completion of this paper; Ms. Lolita A. Dulay, the secretary, who keeps every suggestion and recommendation accurate;

Dr. Manuel T. Caingcoy and Dr. Albert A. Villanca, for their insights and feedback throughout the research proceedings and at the same time as inter-coders for making this paper reliable.

Ms. Shaunell Mary J. Sayson and Ms. Lorelei C. Talose, for their assistance and dedicated involvement in every step throughout the process, this paper would have never been accomplished.
To the participants from the main campus, external centers, and certificate of teaching, for their warm acceptance, willingness, and openness in providing the researcher the necessary data and information.

To my friends, relatives, and co-workers for they are my source of strength and inspiration who always shared moral and spiritual support in my journey and to all those who extended their help not mentioned above, thank you so much.

\section{REFERENCES}

[1]. G. Abbot AV, Peters RK and Volgel ME. (1990). Type u behavior and exercise: A follow-up study of coronary patients. Journal of Psychosomatic Research. 34: 153-162.

[2]. Aboulghasemi A. 2002. Test Anxiety. Ardebil.nikamoz pub.

[3]. Alessandri, G., Caprara, G. V., \& Tisak, J. (2012a). The unique contribution of positive orientation to optimal functioning: Further explorations. European Psychologist, 17(1), 44-54. doi: 10.1027/1016-9040/a000070.

[4]. Alessandri, G., Vecchione, M., Tisak, J., Deiana, G., Caria, S., \& Caprara, G. V. (2012b). The utility of positive orientation in predicting job performance and organizational citizenship behaviors. Applied Psychology, 61(4),669-698.doi: 10.1111/j.14640597.2012.00511.x

[5]. Aljo, G.S., Tancinco, N.P. (2016). Faculty Performance and Students' Academic Achievement in the Licensure Examination for Teachers of Naval State University. College of Education, Naval State University, Naval, Biliran, 6560 Philippines. IOSR Journal of Research \& Method in Education, Volume 6, Issue 4 Ver. II, PP 01-10. www.iosrjournals.org

[6]. Bailey J. (2008). First steps in qualitative data analysis: transcribing. Family Practice, 25, 127-131.

[7]. Baker-Doyle, K.J., Petchauer, E. (2015). Rumor has it: Investigating teacher licensure exam advice networks. Teacher Education Quarterly, 3-32.

[8]. Baumeister, R. F., Campbell, J. D., Krueger, J. I., \& Vohs, K. D. (2003). Does high self-esteem cause better performance, interpersonal success, happiness, or healthier lifestyles? Psychological Science, 14(3),1-44. doi: 10.1111/1529-1006.01431.

[9]. Beck, A. T., \& Alford, B. A. (2014). Depression: causes and treatments (2nd ed). Philadelphia: University of Pennsylvania Press. Retrieved from http://www.ebrary.com

[10]. Berk, L.E. (2000). Child Development (5th ed.). Boston: Allyn and Bacon. 23-38.

[11]. Boni N. (2004). Exercise and physical fitness. Journal of Australasian Center for Policing Research, 10: $1-6$. 
[12]. Coping with and Managing Stress. Boundless Pschology. Retrieved on January 30, 2019. Retrieved at: http://www.boundless.com//psychology/definition/cult ural-norms

[13]. Bronfenbrenner, U. (1990). Discovering what families do. In Rebuilding the Nest: A New Commitment to the American Family. Family Service America http://www.montana.edu/www4h/process.html

[14]. Brophy, J. \& Bawden, D. (2005). Is Google enough? Comparison of an internet search engine with academiclibrary resources. Aslib Proceedings, 57, 498-512.

[15]. Buenafe, Mario B. (2010). "Professionalism and performance of the faculty and non-teaching personnel of data center college of the philippines", Unpublished Master's Thesis, University of Northern Philippines, Vigan, Ilocos Sur.

[16]. Cadiz, Lenaida. (2010). Professionalism and performance of the faculty-respondents in selected universities and colleges in cordillera administrative region, Unpublished doctoral dissertation, University of Northern Philippines, Vigan, Ilocos Sur.

[17]. Caprara, G. V., Steca, P., Alessandri, G., Abela, J. R., \& McWhinnie, C. M. (2010). Positive orientation: Explorations on what is common to life satisfaction, self-esteem, and optimism. Epidemiologiae Psichiatria Sociale, $19(1), \quad 63-71$. doi:10.1017/S1121189X00001615

[18]. Caviness, K. (2009). Food for thought the importance of nutrition for cognitive and physical well-being. Liberty University.

[19]. CHED, (2004). Commission on Higher Education Order (CMO) No. 30, series 2004. "The revised teacher education curriculum."

[20]. Chung, S., Hoerr, S., Levine, R., \& Coleman, G. (2006). Processes underlying young women's decisions to eat fruits and vegetables. Journal of Human Nutrition \& Dietetics, 19(4), 287-298. Retrieved September 30, 2007, from Academic Search Premier database.

[21]. Clemente, J.A., Belleza, D., Yu, A., Catibog, E.V.D., Solis, G., \& Laguerta, J. (2008). Revisiting the Kapwa Theory: Applying Alternative Methodologies and Gaining New Insights. Philippine Journal Of Psychology, Vol 41 No 2, pp. 1-32.

[22]. Colaizzi, P. F. (1978). Psychological research as the phenomenologist views it. In R. S. Valle \& M. King (Eds.), Existential phenomenological alternatives for psychology (pp. 48-71). New York, NY: Plenum.

[23]. Creswell, J. W. (2007). Qualitative inquiry and research design: Choosing among five traditions. Retrieved

from https://www.researchgate.net/publication/286504139_ Qualitative_Research_Method_-_Phenomenology

[24]. De Charentenay, P. SJ (2020). A filipino practice of faith. A Jesuit, Filipino, and Asian Ecclesiastical Faculty of Theologyi. Retrieved from https://www.lst.edu/community/article-archives/712a-filipino-practice-of-faith-p-de-charentenay-sj
[25]. De Geus. (1993). Regular exercise and aerobic fitness in relation to psychological make up and psychological stress reactivity. Psychosomatic Medicine, 55(4): 346-363.

[26]. Denzin N. and Lincoln Y. (Eds.) (2000). Handbook of Qualitative Research. London: Sage Publication Inc.

[27]. Dodeen, H. (2015). Teaching Test-Taking Strategies: Importance and Techniques. Psychology Research, February 2015, Vol. 5, No. 2, 108-113.

[28]. Dowling, M. (2007). From Husserl to van Manen. A review of different phenomenological approaches. International Journal of Nursing Studies, 44, 131-142. DOI: 10.1016/j.ijnurstu.2005.11.026.

[29]. Eichner, K. V., Kwon, P., \& Marcus, D. K. (2014). Optimist or optimistic? A taxometric study of optimism. Psychological Assessment, 26(3), 10561061. doi: $10.1037 /$ pas0000010

[30]. Esmeralda, A.B., \& Espinosa, J. P. (2015). Teacher education graduates' performance as predictor of licensure examination for teachers' results. JPAIR Multidisciplinary Research, https://doi.org/10.7719/jpair.v21i1.330.

[31]. Fredriksson, M., \& Corméry, S. W. (2015). Breaking down positive orientation to self-esteem, optimism and life satisfaction: what predicts test anxiety? Psychology C, Springerlink. Örebro University.

[32]. Freeman, N. P.M. (2011). Credibility and the professor: the juxtaposition of student perceptions and instructor beliefs. Department of Communication, University of Central Missouri. Retrieved from https://pdfs.semanticscholar.org/8dba/04c0b8f4ee266 6d2f866ca9cce55b46ab00a.pdf

[33]. Garcia, G. (2013). Academic performance as determinant to pass the licensure examination for teachers. JPAIR Institutional Research, 2, 69-75. doi:10.7719/irj.v2i1.258.

[34]. Giglio, Kate, (2009) Rand Education Publishing, Teacher Qualification and Student Achievement in Urban Schools, p.10

[35]. Giorgi, A. (2009). The descriptive phenomenological method in psychology: A modified Husserlian approach. Pittsburgh, PA: Duquesne University Press.

[36]. Gottlieb, B. H., and Bergen, A. E. (2010). Social support concepts and measures. Journal of Psychosomatic Research, 69 (2010) 511-520.

[37]. Heward, W. L., (2003). Ten faulty notions about teaching and learning that hinder the effectiveness of special education, Journal of Special Education Vol. 36/No. 4/2003.

[38]. Hillman CH, Erickson KI, Kramer AF. Be smart, exercise your heart: Exercise effects on brain and cognition. Nature Reviews Neuroscience. 2008; 9(1):58-65.

[39]. Jabr, F. (2013) 'Why the brain prefers paper', Scientific American, vol. 309, p. 48.

[40]. Jeong, H. (2012) 'A comparison of the influence of electronic books and paper books on reading 
comprehension, eye fatigue, and perception', Electronic Library, vol. 30, pp. 390-408.

[41]. Krashen, S. \& Lee Brown C. (2006). What is Academic Language Proficiency? http://www.sdkrashen.com/articles/Krashen_Brown_ ALP.pdf

[42]. Lahey, M., Rosen, S. (2002). Dietary factors affection learning behavior. Retrieved from http://childrensdisabilities.info

[43]. Lonwell-Grice, R., Mcilheran, J., Schroeder, M., Scheele, S. (2013). The effect of tutoring on math scores for the Praxis I exam. The Learning Assistance Review. (18)1, p. 47-57.

[44]. Mack, N., Woodsong, C., Macqueen, K. M., Guest, G., Namey, E. (2005). Qualitative Research Methods: A Data Collector's Field Guide. Research Triangle Park, North Carolina 27709, USA. Retrieved from http://www.fhi.org

[45]. Majeed, N. K. (2016). Parental social support: its role in upbringing of children. International Education \& Research Journal, E-ISSN No: 2454-9916 Volume 2, Issue 11.

[46]. Marshall, C. \& Rossman, G. B. (2010). Designing Qualitative Research (5th ed.). Thousand Oaks, CA: Sage Publications.

[47]. McCroskey, J. C., Valencic, K. M., \& Richmond, V. P. (2004). Toward a general model of instructional communication. Communication Quarterly, 52, 197 210 .

[48]. McGraw J. (2002). Life strategies for Teens. Simon \& Schuster Adult polishing Group, New York. pp. 8591.

[49]. Mee, J. (2000). Statistical evaluation of the effectiveness of a preparatory study program for the teacher certification examination in physical education at Southern Connecticut State University.

(Dissertation).

[50]. Miyasaka, J.R. (2000). A framework for evaluating the validity of test preparation practices. A paper presented at the Annual Meeting of the Educational Research Association Retrieved from http://files.eric.ed.gov/fulltext/ED454256.pdf. Retrieved on April 4, 2019.

[51]. Morrow, R., Rodriguez, A. and King, N. (2015). Colaizzi's descriptive phenomenological method. The Psychologist, 28(8), 643-644.

[52]. Myers, S. A., \& Bryant, L. E. (2004). College students' perceptions of how instructors convey credibility. Qualitative Research Reports in Communication, V, 22-27.

[53]. Narimani M. (2000). Examine Prevalence of test anxiety, and causes test anxiety and coping styles among students. University of MohagheghArdabili.

[54]. Nasiri, R., Mirkhan, I., Jahanmahin, M., Khademi, Y. (2015). Investigation the effect of regular physical activity on test anxiety and procrastination in students. Journal of Novel Applied Sciences, 4 (9): 981-986.

[55]. Nyangena, E., Getanda, A., \& Ngugi, S. (2013). Factors influencing success of Bachelor of Science in Nursing graduates in nursing council of Kenya
Licensure Examinations. Baraton Interdisciplinary Research Journal, 3(1), 11-21.

[56]. OECD. (2001b). Report on Hungary/OECD seminar on Managing Education for Lifelong Learning, 6-7 December 2001, Budapest.

[57]. Ozbay, F., Johnson, D. C., Dimoulas, E., Morgan, C. A., Charney, D., \& Southwick, S. (2007). Social support and resilience to stress: from neurobiology to clinical practice. Psychiatry (Edgmont (Pa.: Township), 4(5), 35-40.

[58]. Pachejo, S. \& Allaga, W. (2013). Academic predictors of the licensure examination for teachers' performance of the Rizal Technological University teacher education graduates. International Journal of Educational Research and Technology, 4(4), 31-40.

[59]. Padilla-Diaz, M. (2006). Phenomenology in Educational Qualitative Research: Philosophy as Science or Philosophical Science?. International Journal of Educational Excellence, (2015) Vol. 1, No. 2, 101-110.

[60]. Pascua J. and Navalta, Jane D. (2011). Determinants of L.E.T. perforamnce of the teacher education graduates in a state university, Research Journal College of Education (COED) Vol. 1 No.a , Nueva Ecija University of Science and TechnologyCabanatuan City , January-December 2006, ISSN 1908-6962.

[61]. Philippine Teachers Professionalization Act of 1994 (Republic Act No. 7836) "An Act to Strengthen the Regulation and Supervision of the Practice of Teaching in the Philippines and Prescribing a Licensure Examination for Teachers and for other Purposes" Retrieved from http://www.chanrobles.com/ republicactno7836.htm

[62]. Pilarta, Mae Amalia B. (2011). Status of public secondary schools of abra, Unpublished doctoral dissertation, University of Northern Philippines, Vigan, Ilocos Sur.

[63]. Quiambao, D.T., Baking, E.G., Buenviaje, L.B., Nuqui, A.V., \& Cruz, R.C. (2015). Predictors of board exam performance of the DHVTSU college of education graduates. Journal of Business \& Management Studies, 1(1), 1- 4.

[64]. Quintana, J. (2014). Filipino Faith in God Likens to the Hebrews. Journalism for the soul. Retrieved from http://journalismforthesoul.com/filipino-faithgod-likens-hebrews/

[65]. Rabanal, G. C., (2016). Academic achievement and LET performance of the bachelor of elementary education graduates, University of Northern Philippines. International Journal of Scientific and Research Publications, 6(6), 455-461.

[66]. Rosenfeld, L. B., Richman, J. M., \& Bowen, G. L. (2000). Social support networks and school outcomes: The centrality of the teacher. Child and Adolescent Social Work Journal, 17, 205-226.

[67]. Ross, A. (2010). Nutrition and its effects on academic performance how can our schools improve? Northern Michigan Undersity. 
[68]. Sahin, Y.G., Balta, S., Ercan, T. (2010). The use of internet resources by university students during their course projects elicitation: a case study. The Turkish Online Journal of Educational Technology, April 2010, volume 9 Issue 2.

[69]. San Miguel, J. (2006). Spoken english proficiency of letran-calamba college students. Paper Presented to research and Development DepartmentLetran Calamba.

[70]. Science Teaching Reconsidered: A Handbook. The National Academies of Sciences Engineering Medicine. National Academy Press, Washington D.C. (2019). Retrieved on December 20, 2019 at https://www.nap.edu/catalog/5287/science-teachingreconsidered-a-handbook.

[71]. Sever, M. (2012). A critical look at the theories of sociology of education. International Journal of Human Sciences [Online]. 9:1. Available: http://www.insanbilimleri.com/en

[72]. Shosha, G. (2012). Employment of Colaizzi’s strategy in descriptive phenomenology: A reflection of a researcher. European Scientific Journal, 8(27), 31-43. Retrieved from http://eujournal.org/index.php/esj/article/view/588

[73]. Singer, L. M. \& Alexander, P. A. (2016) 'Reading across mediums: effects of reading digital and print texts on comprehension and calibration', The Journal of Experimental Education, vol. 85, no. 1, pp. 155172.

[74]. Spinelli, E. (2005). The interpreted world: An introduction to phenomenological psychology. Thousand Oaks, CA: Sage Publications, Ltd.

[75]. Steptoe A \& Cox S. (1988). Acute effects of aerobic exercise on mood. Health psychology, 7: 329-340.

[76]. Strayhorn, T. L. (2008). The Role of Schools, Families, and Psychological Variables on Math Achievement of Black High School Students. The High School Journal, Volume 93, Number 4, Summer 2010, pp.177-194.

[77]. Structural-Functional Theory in Sociology: Definition \& Examples. (2015). Retrieved from https://study.com/academy/lesson/structuralfunctional-theory-in-sociology-definition-examplesquiz.html.

[78]. Swanson, H. L., \& Sachse-Lee, C. (2000). A metaanalysis of single-subjectdesignintervention research for students with LD. Journal of Learning Disabilities, 38, 114-136.

[79]. Sweetnam, K. R. (2003). Test-taking strategies and student achievement. Retrieved from http://www.cloquet.k12.mn.us/chu/class/fourth/ks/stra tigies.htm

[80]. Visco, D. (2015). Predictors of performance in the licensure examination for teachers of the graduates of higher education institutions in Abra. International Journal of Management Research and Business Strategy, 4(1), 181-191.

[81]. Wall, T. (2008). Evaluation of the impact of participation in the T.E.S.T examination preparation program on elementary education teacher candidate C-BASE and Praxis II performance (Dissertation).
[82]. Wall, T.J., Johnson, B., Symonds, M.L. (2012). Preparing to the pass the physical education praxis-II examination: increasing teacher candidate testwiseness, self-efficacy, and content knowledge in the era of accountability. Journal of Assessment and Accountability in Educator Preparation. 2(1), p. 36-47.

[83]. Wojnar, D. M., \& Swanson, K. M. (2007). Phenomenology: An exploration. Journal of Holistic Nursing, 25, 172-180. DOI: 10.1177/0898010106295172.

[84]. Wolfe, P., Burkman, A., \& Streng, K. (2000). The science of nutrition. Educational Leadership, March.

[85]. World Values Survey (2006). Retrieved from www.worldvaluessurvey.com on April 2, 2008.

[86]. Wuthnow R. (2002). Religious involvement and status-bridging social capital. JSci Study Relig ;41:669-84.

[87]. Zweirs, J. (2004). The third language of academic english. http://www.makassed.org.lb/Article/the\%20third20\%1 ang\%20all.pdf 